\title{
Fresh-State Properties of Mortars with Recycled Glass Aggregates: Global Unification of Behavior
}

\author{
José Manuel Gómez-Soberón (D), ${ }^{1}$ Francisca Guadalupe Cabrera-Covarrubias, ${ }^{2}$ \\ Jorge Luis Almaral-Sánchez, ${ }^{2}$ and María Consolación Gómez-Soberón ${ }^{3}$ \\ ${ }^{1}$ Barcelona School of Building Construction (EPSEB), Polytechnic University of Catalonia, Barcelona 08028, Spain \\ ${ }^{2}$ Faculty of Engineering Mochis, Autonomous University of Sinaloa, Los Mochis 81210, Mexico \\ ${ }^{3}$ Civil Engineering School, Metropolitan Autonomous University, Mexico City, Mexico
}

Correspondence should be addressed to José Manuel Gómez-Soberón; josemanuel.gomez@upc.edu

Received 17 April 2018; Accepted 3 September 2018; Published 25 September 2018

Academic Editor: Jun Liu

Copyright ( 2018 José Manuel Gómez-Soberón et al. This is an open access article distributed under the Creative Commons Attribution License, which permits unrestricted use, distribution, and reproduction in any medium, provided the original work is properly cited.

\begin{abstract}
Due to the current problems related to the generation of diverse wastes and the extraction of nonrenewable materials to be used in the construction sector, the alternative use of waste glass could be a sustainable option with environmental and economic benefits, in case of being feasible its use as a replacement of the usual aggregates to manufacture recycled mortars. In this research, one presents a study of the fresh-state properties of the mortars containing 15, 30, 60, and $100 \%$ recycled glass aggregates as a replacement for the usual aggregate, providing the experimental results of consistency, density, and air content. Using the experimental results, and by means of a numerical and statistical analysis of these, a diagram of triple interaction that allows us to unify the behavior of the studied properties is constituted; making feasible with this, the prediction of the behavior of these properties with respect to variables as their ratio water/cement, aggregate/cement, and different percentages of replacement of aggregates.
\end{abstract}

\section{Introduction}

The application of materials derived from recycling is an alternative that should be promoted nowadays, as they may be capable of providing suitable properties to the elements to which they are added, even being favorably comparable to the traditional "virgin" materials that they replace [1]. A large amount of the natural materials currently extracted (in 2002, 55 billion tons) are used-directly or indirectly-in construction ( $42 \%$ of the total material extracted) [2].

As a result, there has emerged the requirement and a need not to waste what have until now been considered "waste" materials to prevent the contamination that their dumping (in a landfill) produces and ultimately to slow the extraction of nonrenewable materials for use in construction. Therefore, the advances in the feasibility of using recycled materials applied to construction may lead to a rational use of the available resources, while also safeguarding natural resources for future generations [3]. Glass is one of the different types of recyclable materials available which may help us to satisfy the demand for construction materials [4], and has been categorized as a solid residue which currently shows a gradual increase in its use; when added to the fact that it is nonbiodegradable, it may cause serious environmental problems in landfills [4-9]. On the contrary, the alternative of reuse is unfeasible in many cases due to problems in collection, the mixture of different qualities, or the economic cost involved [10]; therefore the alternative of recycling as a building material seems feasible as a mitigation of its own condition $[7,11,12]$.

Glass is quite easily segregated from other residues, and the study of its physical and chemical characteristics has led to experimentation in its ability to replace "natural" sands in mortars and concrete [13]. This type of praxis is considered ecofriendly, of particular interest in certain construction applications (waterproofing in the structure, resistance 
properties, durability, and aesthetics), and even on occasion for its profitability $[4,14]$. However, for the residue to bond effectively with the matrix of these composites, its properties and resulting products must be established, in order to ensure the suitability of the new recycled composite for use in construction [13].

Previous studies into the behavior of the properties of recycled mortars that incorporate recycled glass aggregate (RGA) to replace the usual aggregate (UA) have dealt with different areas, such as the effect of the quantity of replacements (substitution percentages of UA by RGA) $[7,8,15]$, the variations attributable to the color of the glass $[10,16]$, the effect of the RGA particle size [17-20], and the side effects caused by the type of RGA and its previous use (e.g., proceeding from glass bottles and cathode ray tubes) $[15,21]$. Similarly, there are also precedents in the use of glass with dust-sized particles as a cement substitute, which has permitted more studies to be included, such as the pozzolanic properties that they provide $[1,22,23]$ and the effect of the size of the dust particles themselves [9, 24].

Previous studies have focused on explaining the behavior of the mechanical properties of the mortars in their hardened state; few have been aimed specifically at the study of their behavior in their fresh state. Although in part this is justified, as the former are the desired properties and the latter should not be ignored, as the final mechanical behavior is partly linked to the behavior in their fresh state.

Regarding the consistency of mortars with recycled glass (RGA substituting UA) (RGM) and in comparison with the usual mortars (UM) of reference, it has been established that higher substitution percentages lead to increases in consistency, which has been shown by the increase of the diameter reported in the flow table test $[15,25]$. As a direct implication of the former, it has been deduced that the water needs of the RGM mixtures can be reduced in order to obtain a similar flow to that of the reference UM and, consequently, a lower is possible water/cement $(w / c)$ ratio without causing later side effects [26]. Similar conclusions were obtained regarding the RGM in which the RGA came from different types of glass (drinks bottles and TV cathode ray tubes); however the latter have greater flow values caused by an increase in their particle size (greater fineness modulus and therefore smaller specific surface) which leads to less need for water to cover the particles [21]. The use of fly ash (FA) or ground-granulated blast-furnace slag (GGBFS) to replace up to $25 \%$ of the cement has also been tested, as well as different RGA contents, showing in this study that the mineral composition of the materials for substitution of the cement and the percentage of RGA used may cause variations in the consistency of the RGM; the previous behavior (exclusive use of RGA in RGM) may even be reversed when $75 \%$ of RGA and $25 \%$ of GGBFS are used [27].

Other studies have managed to stabilize the flow of RGM with different RGA contents by means of superplasticizer additives; contents of between 0.5 and $1.5 \%$ of superplasticizer per weight of cement manage to establish as a constant the quantity of water needed for flows of similar consistency (between 243 and $259 \mathrm{~mm}$ ) with up to $75 \%$ of RGA [7, 12]. In a similar study (the use of superplasticizer and RGA), which also made changes in the size of the particles, the previous behavior remained in force, with the exception that the increase in RGA particle size permitted a reduction in the additive contents to be used, i.e., the increase in the RGA particles causes an increase in flow, due to the RGA showing a smoother surface and an absorption coefficient close to zero [19].

Another similar case is presented, of RGM with $100 \%$ of glass from drink bottles, and RGM with $100 \%$ of cathode ray tube glass (CRT) (particle size $<5 \mathrm{~mm}$ ) has shown an increase in the fluidity due to the smoother surface of the glass and a lower water absorption capacity. However, in this very same study, RGM with smaller particles caused a reduction in fluidity, most notably in the mixture with the finest particles $(<600 \mu \mathrm{m})$, this behavior being attributed to the fineness of the aggregate with the greatest total surface per unit of volume [20]. The study presented by Öznur Öz et al. [28] reported similar reduction behavior; this as a consequence of the use of RGA in powder form.

A contrary situation is reported in another study, which shows that the use of glass (irrespective of its color) reduces the flow capacity, showing reductions inverse to the increase of RGA used, this being due to the irregular shape and lower density of its particles [16]. Another work coincides with this behavior, as the increase in substitution of RGA by UA, required higher doses of water to reach the same value by means of the flow table [17]. On the contrary, in another study, no significant differences were shown between the water requirements of the RGM and the reference UM; this behavior (compared with other studies) was attributed to the different types of glass used and the water absorption, which depends on the size of the aggregates [29].

Regarding the density property of the mortars in their fresh state, previous studies show reductions in the RGM, presenting an inverse behavior to the increased RGA substitution for $\mathrm{UA}$; this is due to the lower specific gravity of the RGA compared with the UA $[16,30]$, as well as the more angular form of the glass compared with the sand, which results in a greater volume of spaces [29]. The opposite is shown in another study, in which $100 \%$ of RGA replaces the $\mathrm{UA}$; the RGA is characterized by two different sizes (studied separately), and both of the final RGMs showed a greater density than the UM. The explanation for this behavior may be the same as in the previous study, in which the density in the fresh state is attributed to the density of the RGA itself compared with the UA, which in this case was due to the use of cathode ray tube glass [25].

Finally, there is very little information in the literature regarding the air content property; among the published works, the use of fine RGA is mentioned (of between 2.36 and $5 \mathrm{~mm}$ ), which results in a greater air content in the mixture due to the irregular shape of the particles, leading to greater relative surface which in turn creates larger areas that retain air voids $[19,31]$. Other studies have also reported greater air contents in RGM, showing increases when the RGA replacement is higher [30, 32], for example, reaching a maximum difference of $54 \%$ for mortar with $100 \%$ RGA (air content of 12.6\%), compared with the reference mortar [29]. This behavior is attributed to the lower density of the 
particles and their shape, with sharper edges showing a greater relation of aspect which allows more air to be retained in the surfaces of the RGA particles; it has also been commented that microcracks have been noticed in the case of transparent glass particles, which could have affected the packing of the aggregates mainly in the case of high contents [16].

Based on the aforementioned, it can be asserted that documental evidence is scarce and therefore the information about the fresh properties of RGM is minimal, which in general makes it difficult to predict the behavior that these mortars can show before manufacture, as they do not present established behavioral tendencies. The aim of this study is to provide a triple interaction diagram with which to predict the $w / c$ ratio, the density, or the air content that the RGM may show with different RGA percentages substituting the UA and with three different aggregate/cement $(a / c)$ ratios. Moreover, it can be used for deciding what percentage of substitution is needed for use in the RGM to obtain a particular density; in general, the link between the fresh-state properties can easily be determined, as well as predicting the ratios shown by the different RGMs from the design phase of the mixtures. Both the diagram, to be presented later, and the regression equations are the result of numerical and statistical analysis performed on the data of an experimental campaign, which establishes the properties of the consistency, density, and air content of the different ratios of $a / c, w / c$, and the replacement factor (RF) in the RGM.

\section{Materials}

Transparent glass residues with a particle size of between 0 and $1.8 \mathrm{~mm}$, obtained from a local waste glass processing company, were used as RGA; specifically, the glass used came from laminated glass (commonly used in windows, doors, and car windscreens). A UA composed of silica sand with the particle size of $0-4 \mathrm{~mm}$ was used to manufacture the reference mortars; the silica sand came from a local supplier of aggregates for construction.

The adjusted granulometric curves of both aggregates, as well as the limits established by the ASTM C144 standard [33], are shown in Figure 1. As the original granulometric profile of the UA was positioned outside the lower limit of the ASTM, and that of the RGA was located above the upper limit of the same, a granulometric adjustment was made to distribute the particle sizes in the two aggregates used; consequently, both granulometric curves conformed-as much as possible-to the limits, also achieving a similarity in profiles. The adjustment procedure involved separating both materials with a no. 30 sieve $(0.59 \mathrm{~mm})$, where the particles that passed through the sieve being established as fine fraction (FF) and those retained in the sieve as coarse fraction $(\mathrm{CF})$; then mixtures of different FF and CF combinations were made until the proportions with the maximum compactness were obtained (RGA and UA separately). In the case of the RGA, the combination that fulfilled the requirement was that of $70 \%$ $\mathrm{FF}$ and $30 \% \mathrm{CF}$; and for UA, the combination was $50 \%$ of each fraction [34]. After making the adjustment, it can be seen in Figure 1 that the adjusted granulometric profile of the RGA is located very close to the upper limit, demonstrating that the majority of these aggregate's particles are composed of fine

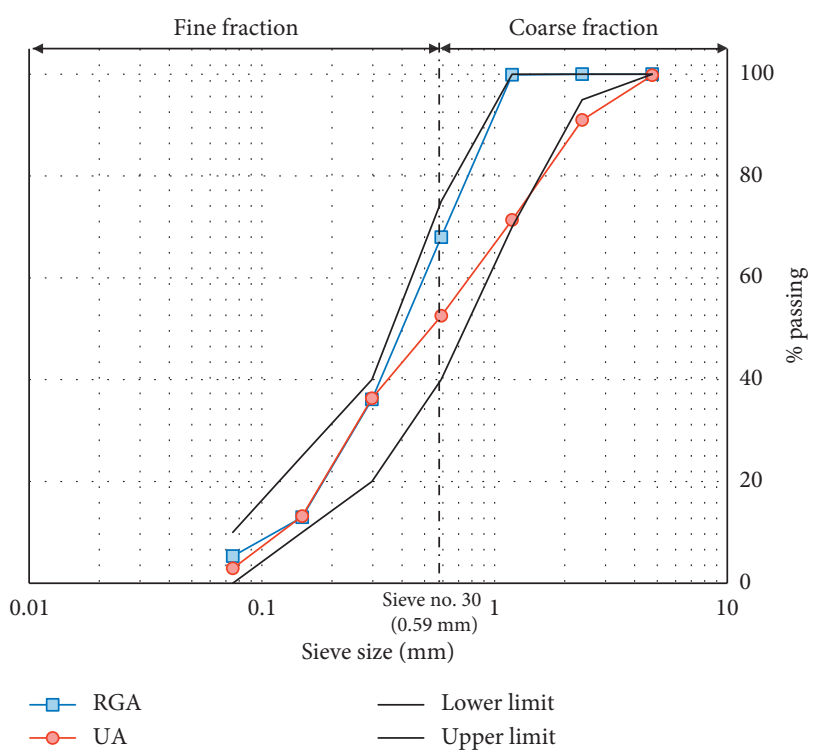

FIgURE 1: Granulometric distribution curves.

particles; in Table 1, the fineness modulus $(\mathrm{FM})=1.8$, which places it outside the desired specified range for sands (2.3 to 3.1, according to the ASTM C33 standard). The opposite is seen in the case of the adjusted profile of UA, generally found within the established limits, with the exception of $4 \%$ of the material which comes from the lower limit (sieve no. 8 $(2.38 \mathrm{~mm})$ ); the MF of the UA (2.4) locates within the desired range for sands. For both aggregates, the percentage of fine particles with sizes less than $75 \mu \mathrm{m}$ is below $10 \%$ (requirement specified by the standards). To sum up, it can be said that the adjustment allows both aggregates to be compared with minimum profile modifications, meaning that the replacement of both materials does not lead to variations of their properties due to the effect of the distribution of their particle sizes; in addition, the adjustment permits their profiles to be closely aligned to that recommended by the standards, thereby guaranteeing better behavior of the mixtures.

Consequently, the procedures specified by the ASTM C128 [35], C136 [36], and C117 standards [37] were carried out in order to determine the general physical properties of the aggregates to be used (Table 1). Significant differences between both aggregates were established for the water absorption coefficient, which for the RGA meant a difference of $1 \%$ with respect to that obtained by the UA. Regarding the dry-state density (OD) and the saturated surface dry (SSD) state, the UA shows slightly higher values than the RGA (107.76 and $134.8 \mathrm{~kg} / \mathrm{m}^{3}$, respectively).

Finally, Portland cement with the usual properties and components, classified as CEM I 42.5 N/SR (UNE EN 197-1: 2011 [38]), was used as a binding material in making the different UM and RGM, along with tap water.

\section{Experimental Campaign}

The experimental campaign was divided into two sections: the first was for obtaining the experimental data, in which 
TABLE 1: Physical properties of the aggregates.

\begin{tabular}{lcc}
\hline Property & RGA & UA \\
\hline Density (OD) $\left(\mathrm{kg} / \mathrm{m}^{3}\right)$ & 2473.84 & 2581.6 \\
Density (SSD) $\left(\mathrm{kg} / \mathrm{m}^{3}\right)$ & 2488.8 & 2623.6 \\
Water absorption $(\%)$ & 0.6 & 1.6 \\
Fineness modulus & 1.8 & 2.4 \\
Materials finer than $75 \mu \mathrm{m} \mathrm{( \% )}$ & 5.3 & 2.9 \\
\hline
\end{tabular}

the procedure and tests for obtaining data were explained and the second was the data analysis, which established the numerical data analysis procedure that allows the regression coefficients and the triple interaction diagram proposed for the unified behavior of the RGM to be obtained.

3.1. Obtaining the Experimental Data. Several mixtures of RGM were made, composed of different percentages of RGA as a UA substitute $(15,30,60$, and $100 \%)$; for each, three different $a / c$ ratios were specified $(3.25,4$, and 4.75$)$. In order to simplify the identification of the RGM studied, the following agreement of nomenclature was established: " $X X \%$ $\mathrm{RGM}-A / B / C$," where $\mathrm{XX} \%$ is the percentage of RGA (or RF) and $A / B / C$ represents the three different ratios of $a / c$ studied $(A=3.25, B=4$, and $C=4.75)$. The reference mortars UM ( $0 \%$ of RGA) for each of the $a / c$ ratios studied were identified as $\mathrm{UM}-A, \mathrm{UM}-B$, and UM- $C$. All the mixtures were designed for an initial $w / c$ ratio of 0.5 . Table 2 shows the amount of materials needed to make the RGM and UM.

The mixing process for each of the mortars implied introducing the RGA and/or the UA along with the total water (obtained from the initial $w / c$ ratio) in the mixing recipient (one minute at rest) to obtain the saturation of the aggregates, introducing the cement later. Then, the recipient containing the materials was placed in the mixer (Mod. E93, Matest brand,) and the mixing procedure was carried out in accordance with point 8.1.3 of the ASTM C305-06 standard [39]. When the mixing was finished, the tests on the mortar behavior in the fresh state were carried out.

3.2. Consistency. Once the mixing process of the mortars had ended, the consistency of the RGM was determined by means of a mortar flow test according to the ASTM C1437 standard [40], using a flow table with specifications conforming to the C230/C230M standard [41]. As a mandatory step in making a feasible comparison of the different mixtures studied, it was decided that they should all reach a flow of $110 \pm 5 \%$ according to the specifications of the ASTM C109/C109M standard [42] (standardized mortar); as a standard mold with a $10 \mathrm{~mm}$ base was used, the diameter sought at the end of the test was $210 \pm 5 \mathrm{~mm}$, which was determined by the average measurement of the diameters of the principal axes passing through the center of the extended sample. If the sample did not present the required flow, more water was added repeatedly, in small amounts, until the desired flow was obtained and the mortar could be considered standardized.
3.3. Density. The density of the previously obtained RGM was determined; for this test, the equipment used was a standard recipient of the one liter, which was also part of the equipment needed for the air content test. The standard mixture was put into the recipient in three successive layers, each individually compacted (20 distributed blows) with a metal tamper with a flat circular section; then in the final layer, a metal ruler was used to skim off any excess mixture. The resulting specimen was then weighed (Mod. ST-4000 Series ST, GRAM Precision brand, accurate to 0.01 grams). When the mixture weight was obtained (deducting the weight of the mold) and considering the volume of the standardized mold to be a known constant, the density of the RGM was determined by means of the following equation:

$$
\rho=\frac{M}{V}
$$

where $\rho=\operatorname{density}\left(\mathrm{g} / \mathrm{cm}^{3}\right), M=$ mass $(\mathrm{g})$, and $V=$ volume $\left(\mathrm{cm}^{3}\right)$.

3.4. Air Content. To finish, the content of the air included in the RGM study samples was tested; the standard equipment for determination being a 1-liter TESTING brand Air Entrainment Meter which included the recipient was also used in the density tests. The test was based on the pressure method (ASTM C231 standard [43]), with the air content of each of the studied RGM being obtained with a calibrated manometer. As validation of the test, the air content was also determined by means of the method described in the ASTM C185-99 standard [44]; this uses the density values of the mortars and materials and the mixture proportions. In this second method, the air content is obtained by means of

$$
\text { air content, volume } \%=100\left[1-\frac{W_{\mathrm{a}}}{W_{\mathrm{c}}}\right] \text {, }
$$

where $W_{\mathrm{a}}=$ actual mass per unit of volume as determined by this test method $\left(\mathrm{g} / \mathrm{cm}^{3}\right)$ and $W_{\mathrm{c}}=$ theoretical mass per unit of volume, calculated on an air-free basis and using the values of the quantities of materials and specific gravities from each of them-see the complete equation in the standard ASTM C185-99.

The reason for the need to validate this property through its determination by two different procedures was in order to be able to differentiate, or corroborate, the values obtained by the different RGM studied; this was necessary when using aggregates with densities and absorption of different values to make RGM or to determine whether this property was sensitive to variation.

3.5. Regression Coefficients and Trend Equations. The results obtained from the tests were used in the statistical analysis software SPSS v24.0.0.0 of IBM for Windows, into which the data were introduced with the aim of finding the regression coefficients that would allow the trend equations to be determined; consequently, the ratios between the RF and the different properties of RGM in the fresh state could be established. It was noticed in the dispersion graphs for each 


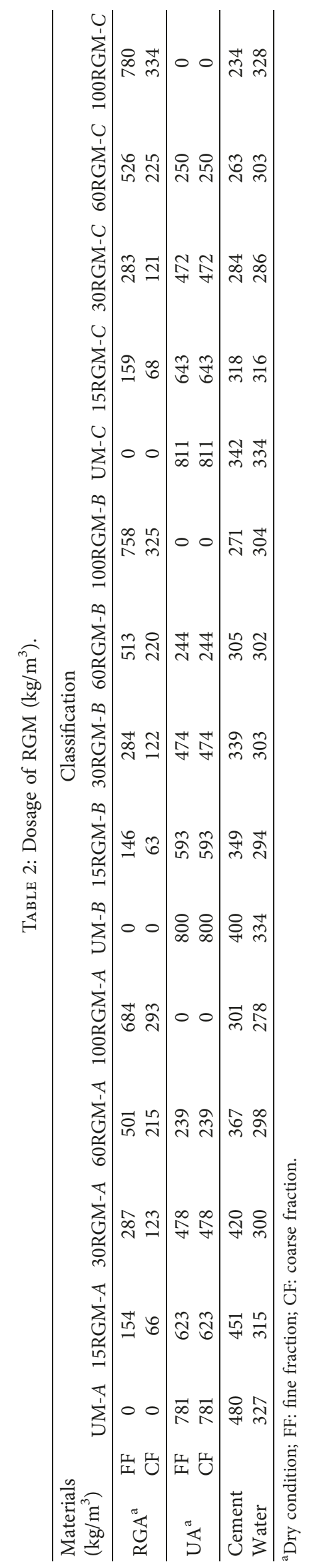


ratio studied that the variables were closer to regressions with curvilinear estimates; additionally, in all the ratios studied, they did not comply with the requisites of linear or simple distribution (distribution of the normal dependent variable, for each value of the independent variable; the variance of the dependent variable distribution is a constant for all values of the independent variable; there is a linear relationship between the dependent variable and each independent variable; and all observations are independent). On the contrary, all the necessary requirements for determining a curvilinear regression are satisfied; in particular, the second grade quadratic regressions adjust better, in accord with the acquirement of the highest $R^{2}$ parameter (measurement of the goodness of the fit or reliability of estimated data model, $R^{2} \leq 1.0$ ). The requirements to be met for a quadratic regression were as follows:

(1) The dependent and independent variables are quantitative

(2) The model's residues are distributed normally and randomly

(3) The quadratic model was adapted to the studied series with a "detached" or damped distribution

In each pair of variables studied, it was considered that the $\mathrm{RF}$ represented the independent variable-because it has no precedent in this area of knowledge-and density, and the $w / c$ ratio and air content were the dependent variables; this allowed the obtained regression equations to be established for the mathematical formulation which best predicted the group of data for the dependent variables. The trend curves were determined by calculating the study points (grouping of independent and dependent variables) by means of adjusting the squared minimums and using the following Equation as the structure of the mathematical formula:

$$
y=a x^{2}+b x+c
$$

where $x=$ value $x_{i}$ of the independent variable; $y=$ value $y_{i}$ of the dependent variable; and $a, b, c=$ constant coefficients of any value, except for $a=0$.

\section{Results and Discussion}

The experimental results of the fresh-state properties of the studied RGM corresponding to the consistency (quantity of water and final $w / c$ ratio), density, and air content are presented in Table 3.

The regression coefficients that defined the different behavior equations of this research were obtained from the previous values by means of quadratic regressions; Figure 2 shows the experimental results of the density, the $w / c$ ratio, and the air content with regard to $\mathrm{RF}$ - for the three different $a / c$ ratios $(A, B$, and $C)$ - as well as the equations with their regression coefficients.

It can be seen that, in the case of the RGM density with regard to RF, a damping ratio is established, which means that the higher the independent variable (RF), the lower the value of the dependent variable (RGM density). The previous behavior is similar (parallel trends) for the different $a / c$ ratios studied, following an initial increasing order in the $a / c$ ratio ( $A$ followed by $B$ and then $C$ ), which causes decreases in the density. When RF is close to $40 \%$, the order between $B$ and $C$ is inverted, which may be due to a balancing or better fit of the particles (RGA and UA) in the RGM with the variable $C(a / c=4.75)$, improving their compactness and, therefore, their density.

With regard to the RF ratio and the dependent variable $w / c$, this shows an ascendant distribution; this should be understood in terms of the need for more water in the RGM as the RF is increased. This is related to the irregular shape of the RGA particles, which generates a greater need for water in order to obtain a standard comparable consistency. In order to corroborate this, the shape of the particles forming the RGA was observed, using a JEOL JSM-6510 scanning electron microscope (SEM) to study the samples previously embedded in a resin and then with their surfaces polished. Figure 3 shows SEM images in which the wavy shape of UA can be seen in Figure 3(a); while Figure 3(b) shows the RGA particles (more angular and of longer proportions).

Regarding the $a / c$ ratio, the established experimental order was ascendant $(A, B$, and $C)$; this is a natural response, as any increase in the aggregate content of a mixture also requires an increase of water (angled and elongated particle shape of the RGA).

As for the representative equations of the air content, it can be seen that the increase of RF causes damping, with two important differential zones: one comprising the values lower than RF $30 \%$ to $60 \%$, which results in a damping of the curves proportional and incremental, and following it, a decelerated damping that tends to a constant (similar behavior to the density property but in the inverse sense).

Using the regression equations presented in Figure 2, the theoretical values that make up the curves of each ratio can be obtained by numerical simulation, thereby establishing the triple action diagram (Figure 4 ) which provides with the unified global behavior of the RGM in the fresh state. The following are some of the observations obtained from the graph:

(i) The behavior of the density reduction due to the effect of the RF might be caused by the low density of the RGA, having an effect on the matrix of the RGM. However, for RF $\geq 53.82 \%$, and with a high $a / c$ ratio $(C)$, the density values of the RGM are similar (in curve $B$ ), thereby losing the effect of the $\mathrm{RF}$ factor in reducing density.

(ii) The bigger the RF, the greater the $w / c$ ratio; this situation is caused by the increase in the need for water in the RGM to obtain the same standardized consistency in the mixtures. The previous behavior is also valid for the $a / c$ ratio, as a mortar mixture containing more RGA (with respect to an equal amount of cement) will need more water (and therefore a higher $w / c$ ratio), which is necessary to give more "mobility" to the aggregates in the mixture (workability). 
TABLE 3: Results of the fresh-state properties of RGM.

\begin{tabular}{|c|c|c|c|c|c|}
\hline & $\begin{array}{l}\text { Water needed for } \\
1 \mathrm{dm}^{3}(\mathrm{~g})\end{array}$ & Final $w / c$ ratio & $\begin{array}{l}\text { Density } \\
\left(\mathrm{g} / \mathrm{cm}^{3}\right)\end{array}$ & $\begin{array}{l}\text { Air content (\%) } \\
\text { ASTM C231 }\end{array}$ & $\begin{array}{l}\text { Air content (\%) } \\
\text { ASTM C185 }\end{array}$ \\
\hline UM- $A$ & 327.35 & 0.68 & 2.18 & 2.0 & 0.2 \\
\hline 15RGM- $A$ & 314.63 & 0.70 & 2.02 & 8.3 & 7.0 \\
\hline 30RGM-A & 300.14 & 0.71 & 1.87 & 13.7 & 13.1 \\
\hline $60 \mathrm{RGM}-A$ & 297.70 & 0.81 & 1.63 & 22.1 & 22.3 \\
\hline 100RGM-A & 278.39 & 0.93 & 1.57 & 22.3 & 22.6 \\
\hline UM- $B$ & 334.44 & 0.84 & 2.16 & 2.0 & 0.2 \\
\hline 15RGM- $B$ & 293.83 & 0.84 & 1.96 & 10.1 & 8.9 \\
\hline 30RGM- $B$ & 303.43 & 0.90 & 1.78 & 16.7 & 16.2 \\
\hline 60RGM- $B$ & 301.54 & 0.99 & 1.57 & 23.6 & 24.1 \\
\hline 100RGM- $B$ & 304.32 & 1.12 & 1.48 & 25.0 & 26.1 \\
\hline UM-C & 334.28 & 0.98 & 2.15 & 1.8 & 0 \\
\hline 15RGM-C & 316.49 & 0.99 & 1.91 & 11.7 & 10.4 \\
\hline 30RGM-C & 286.15 & 1.01 & 1.77 & 17.4 & 16.8 \\
\hline 60RGM-C & 302.84 & 1.15 & 1.59 & 22.4 & 22.7 \\
\hline 100RGM-C & 327.67 & 1.40 & 1.50 & 22.9 & 23.8 \\
\hline
\end{tabular}

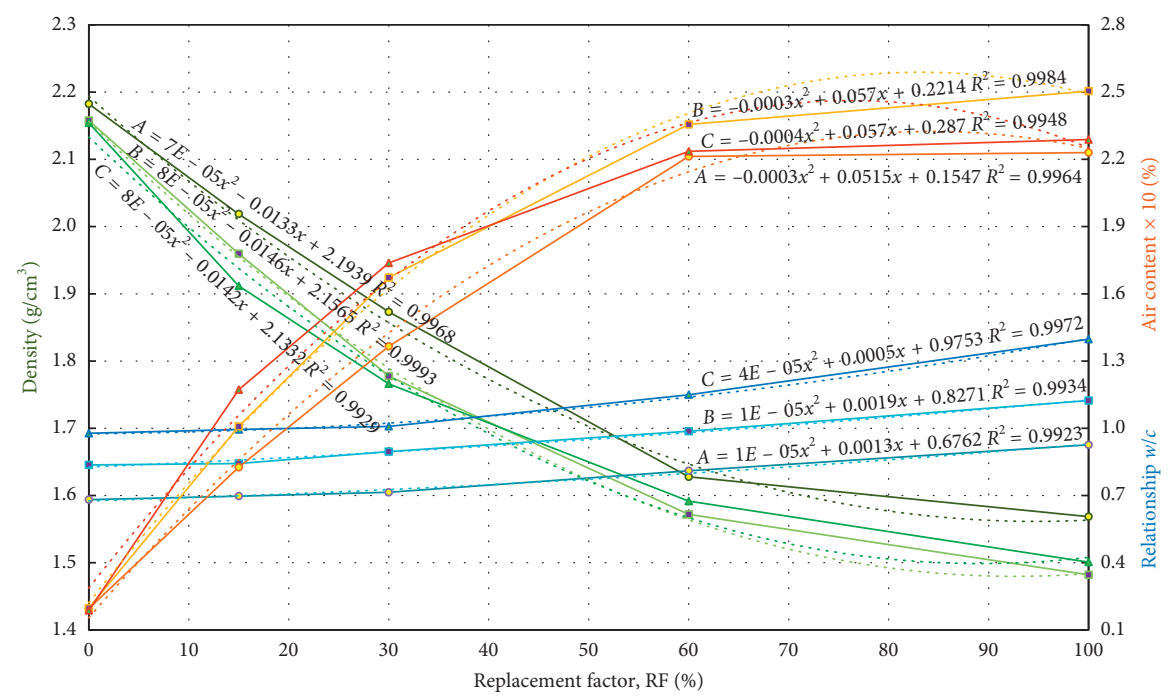

FIgURE 2: Experimental values of the UM and RGM, and regression equations with their resulting reliability.

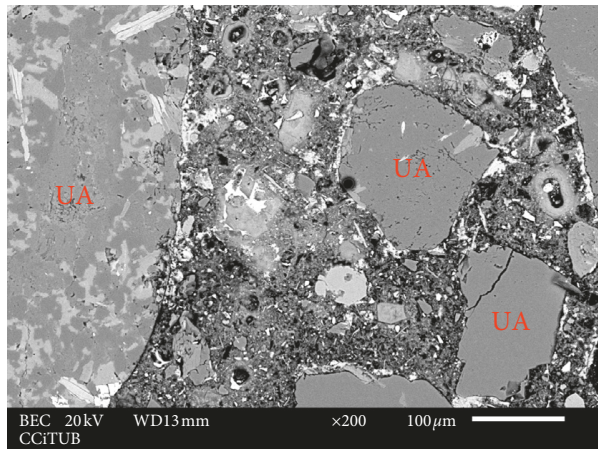

(a)

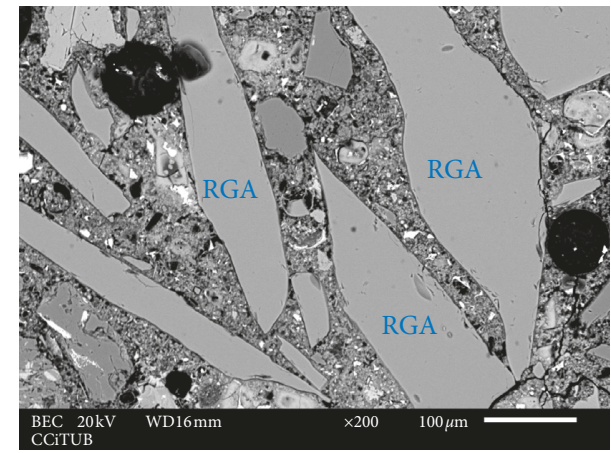

(b)

Figure 3: SEM images. (a) UM-B (UM with 100\% UA). (b) 30RGM-B (RGM with $30 \%$ RGA). 


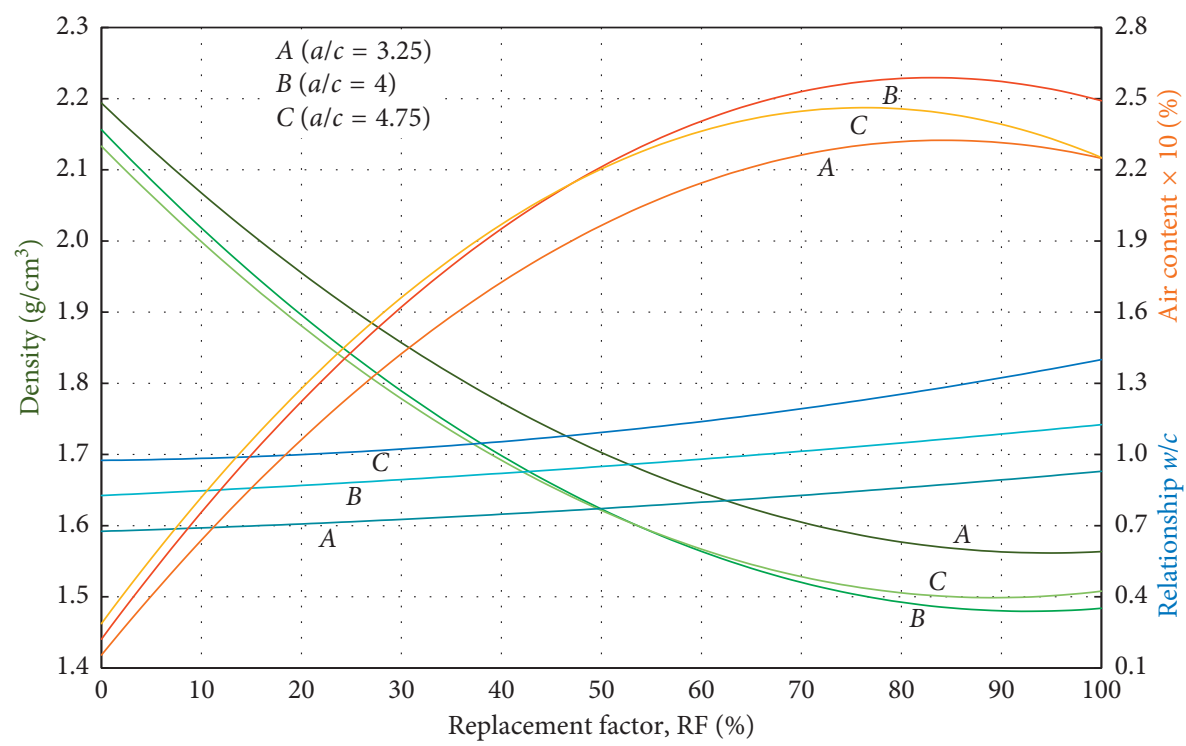

FIgURE 4: Triple interaction diagram of the fresh-state properties of the RGM.

(iii) The effect of the increase in REF leads to greater air content in the RGM; this is due to the irregular shape of the RGA particles, which cannot obtain the best fit to improve the mixture's compactness, while also causing more air to be trapped between them. This effect also holds true for a higher $a / c$ ratio; however, mortars with $\mathrm{RF} \geq 47.06 \%$ and ratio $C$ show a similar behavior to that reported in the densities, with the difference that here it is in the opposite, or decreasing, sense; the air content in the mortar is maintained even when the quantity of RGA is increased.

The triple interaction diagram obtained has two different forms of use, which allow the reference values of design and fresh-state properties to be obtained simply and quickly from different RGM mixtures with any value of RF. Examples of the diagram's use might be as follows:

(iv) For predictive use in the design of an RGM mixture. One example might be defined as follows: what content range of RF should be used to obtain an RGM with a determined density or air content?

(v) For estimation or revision of an RGM mixture. For example, what density and air content does an RGM show when starting from the data of the RF and the a/c ratio?

With the aim of calibrating the degree of certainty in the obtained diagram, Table 4 presents the theoretical values of the different properties studied and approximation errors (which were determined by the previously prepared regression equations). Identical RF contents were established for a comparison of the estimated and experimental values. In the case of the properties of the $w / c$ ratio and the RGM density, the maximum approximation error was of only $0.02 \%$, with a general average error of only $0.0067 \%$, thereby clearly validating a correct application. Regarding the air content, the maximum approximation error established was of $0.53 \%$ (UM-C), with a general average error of $0.0847 \%$.

With the aim of revising the proposed diagram's adaptability strength, the results presented in previous works were included in order to observe their relative graphic positioning. The resulting graph is shown in Figure 5, with the addition of previous research (all broken lines); the green lines refer to the density (values on left axis), the blue lines show the $w / c$ ratio, and the red line shows the air content.

Regarding the density properties, the values of Tan and Du's 2013 research [16] establish densities higher than those of this study. However, they are similar for $\mathrm{RF}=0 \%$, which indicates that these variations do not originate (at least directly) in the difference between the density of the UA in their study and that used in this research. It should be pointed out that, in this research, the RF effect has very little emphasis on the change in this property, which could be explained by the low a/c ratio used (2.75); as they contain fewer aggregates and therefore a lower amount of RGA, they cause no significant losses of density. Finally, the direction of their damping curves does coincide with that shown in this research, although in this case it is closer to a straight sloping line than to a curve typical of a quadratic equation.

In the case of the data of Penacho et al. [29], at up to $\mathrm{RF}=20 \%$, they show density values inferior to the curves of the proposed diagram; nevertheless at higher RF values, the density is greater and the trend decrease regarding the RF is also weakened, although at a lower rate of change and with a similar $a / c$ to the diagram proposed for $B$. In this last case, the deviation may be explained by the influence of the RGA density (an average of $1030 \mathrm{~kg} / \mathrm{m}^{3}$ ), being $42 \%$ lower than that used in this research; the former also leads to decreases in density for high RF values, although with fewer accentuated changes than those shown in the diagram (effect of the RGA density). 
TABLE 4: Theoretical values of the RGM properties and approximation errors.

\begin{tabular}{|c|c|c|c|c|c|c|}
\hline \multirow{3}{*}{ Mortars of study } & \multicolumn{6}{|c|}{ Property } \\
\hline & \multicolumn{2}{|c|}{ Final $w / c$ ratio } & \multicolumn{2}{|c|}{ Density $\left(\mathrm{g} / \mathrm{cm}^{3}\right)$} & \multicolumn{2}{|c|}{ Air content (\%) } \\
\hline & $\begin{array}{l}\text { Estimated } \\
\text { value }\end{array}$ & $\begin{array}{l}\text { Approximation } \\
\text { error }^{\mathrm{a}}(\%)\end{array}$ & $\begin{array}{l}\text { Estimated } \\
\text { value }\end{array}$ & $\begin{array}{l}\text { Approximation } \\
\operatorname{error}^{\mathrm{a}}(\%)\end{array}$ & $\begin{array}{l}\text { Estimated } \\
\text { value }\end{array}$ & $\begin{array}{l}\text { Approximation } \\
\text { error }^{\mathrm{a}, \mathrm{b}}(\%)\end{array}$ \\
\hline UM- $A$ & 0.68 & 0.01 & 2.19 & 0.01 & 1.55 & 0.21 \\
\hline $15 \mathrm{RGM}-A$ & 0.70 & 0.00 & 2.01 & 0.00 & 8.58 & 0.04 \\
\hline $30 \mathrm{RGM}-A$ & 0.73 & 0.02 & 1.86 & 0.01 & 14.25 & 0.04 \\
\hline 60RGM-A & 0.80 & 0.01 & 1.65 & 0.01 & 21.45 & 0.03 \\
\hline 100RGM- $A$ & 0.93 & 0.00 & 1.56 & 0.00 & 22.49 & 0.01 \\
\hline $\begin{array}{l}\text { Approximate mean } \\
\text { error }^{c}(\%)\end{array}$ & & 0.01 & & 0.01 & & 0.07 \\
\hline UM- $B$ & 0.83 & 0.01 & 2.16 & 0.00 & 2.21 & 0.12 \\
\hline $15 \mathrm{RGM}-B$ & 0.86 & 0.02 & 1.96 & 0.00 & 9.99 & 0.01 \\
\hline 30RGM- $B$ & 0.89 & 0.00 & 1.79 & 0.01 & 16.22 & 0.03 \\
\hline 60RGM- $B$ & 0.98 & 0.01 & 1.56 & 0.01 & 24.05 & 0.02 \\
\hline 100RGM- $B$ & 1.13 & 0.00 & 1.48 & 0.00 & 24.91 & 0.01 \\
\hline $\begin{array}{l}\text { Approximate mean } \\
\text { error }^{\mathrm{c}}(\%)\end{array}$ & & 0.01 & & 0.00 & & 0.04 \\
\hline UM-C & 0.98 & 0.00 & 2.13 & 0.01 & 2.87 & 0.53 \\
\hline 15RGM-C & 0.99 & 0.00 & 1.94 & 0.01 & 10.58 & 0.10 \\
\hline 30RGM-C & 1.02 & 0.01 & 1.78 & 0.01 & 16.61 & 0.04 \\
\hline 60RGM-C & 1.14 & 0.01 & 1.57 & 0.02 & 23.63 & 0.06 \\
\hline 100RGM-C & 1.40 & 0.00 & 1.51 & 0.00 & 22.52 & 0.02 \\
\hline $\begin{array}{l}\text { Approximate mean } \\
\text { errorc }^{c}(\%)\end{array}$ & & 0.01 & & 0.01 & & 0.15 \\
\hline
\end{tabular}

${ }^{a}$ Approximation error $(\%)=\mid($ experimental value-estimated value $) /($ experimental value $) \mid{ }^{b}$ Experimental value $=($ experimental value ASTM $\mathrm{C} 231+$ experimental value ASTM C185/2. ${ }^{\mathrm{c}}$ Average error $(\%)=\left(\sum_{i=1}^{n}\right.$ Approximation error $) / n$.

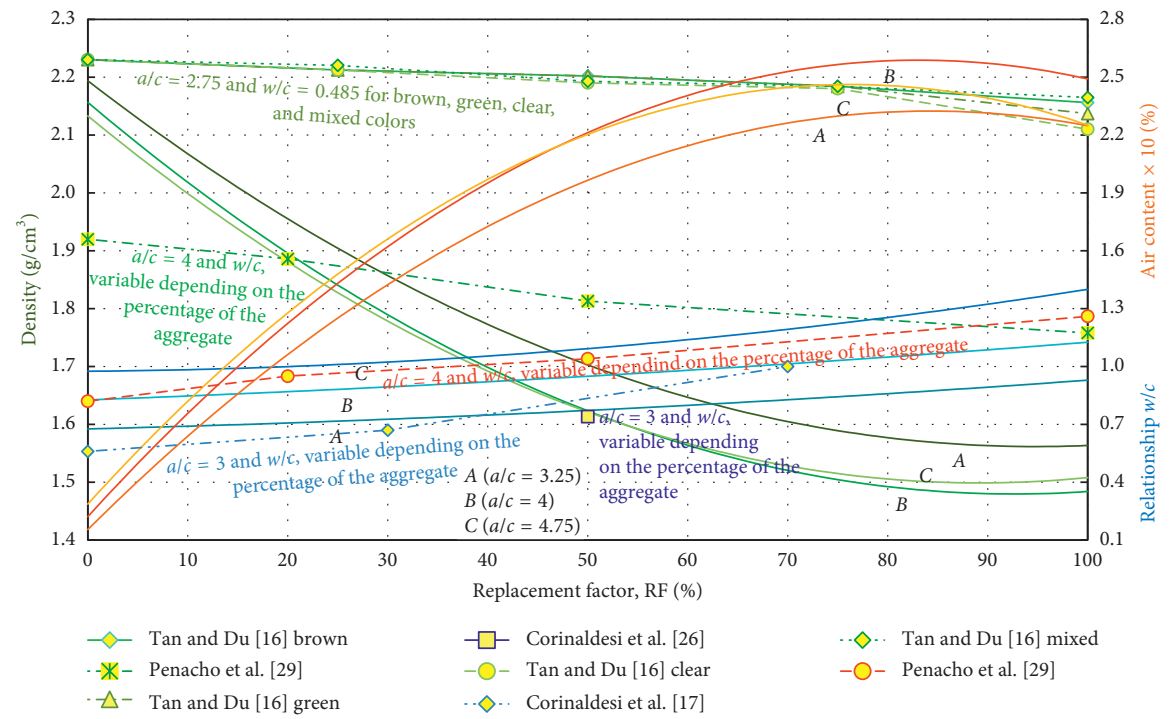

Figure 5: Triple interaction diagram and results of previous studies.

In regard to the particular case of the $w / c$ ratio, two previous studies provide results applicable to the diagram of this research: Corinaldesi et al. [17] and Corinaldesi et al. [26], both allowing the curves proposed for this property in the diagram to be validated. Both studies used an $a / c=3$ ratio, close to the curve $A$ of the diagram proposed here. In the first study, when $\mathrm{RF} \leq 40 \%$, the order, position, and precision of the data can be considered acceptable and congruent with the proposed diagram; this is also the case of the second study, with the only value provided being $\mathrm{RF}=50 \%$. Beyond $\mathrm{RF}>40 \%$, the data are positioned above the curve $A$ $(a / c=3.25)$ with a type of the ascendant curve very similar to those found in this research.

Finally, given the scarcity of previous information about the properties of the air content of RGM, only the data of one study were suitable for inclusion in the proposed diagram: the work of Penacho et al. [29], with the RFs of 0, 20, 50, and $100 \%$, showing an ascendant curve with a distribution like 
those shown in this research; however, the air content figures were lower than those proposed. The nondirect application of these data to the proposed diagram may be explained by the characteristics of the aggregates used, described as significantly more angular than the UA [29]. In a paper present in the literature, with the substitution percentages of $25,35,50$, 75 , and $100 \%$ of replacement and with similar experimental campaign, they report that the incorporated air content increased with the replacement of UA by RGA in almost linear relation $\left(R^{2} \approx 0.99\right)$, similar to that presented in this paper [30].

Once the previous studies had been analyzed and compared with the target diagram of this study, it was possible to validate its use in predicting the fresh-state properties of RGM that contains RGA of similar characteristics to those used. As a necessary future objective, it justifies the need to prepare a more universal or extensive diagram in which additional experimental data with more variables can be included; the analysis should also include values of the continuity of this research as well as those of other studies. Obtaining this universal diagram will improve the prediction and application of RGM use.

\section{Conclusions}

The following conclusions were obtained from the work presented:

(i) Having the experimental data of the RGM permitted the triple interaction diagram to be made, which allowed the behavior of the properties in the fresh state to be unified; this focused both on the design phase of the mixtures and the prediction of their properties, with the RF being an important and decisive parameter

(ii) The data obtained from the diagram may be useful in the composition of other new diagrams in which the hardened-state properties of RGM, such as compressive strength, can be included

(iii) In order to obtain more reliable predictions, it is recommended to verify that the characteristics of the RGA (particle size, density, etc.), to be evaluated, are similar to those used in the creation of the diagram obtained in this investigation

(iv) More types of tests should be carried out on RGM, which will provide a broader knowledge of its properties; consequently, diagrams containing different variables for multiple alternative uses can be prepared

\section{Data Availability}

Data supporting this research article are available from the corresponding author upon request.

\section{Conflicts of Interest}

The authors declare that there are no conflicts of interest regarding the publication of this paper.

\section{Acknowledgments}

The authors thank the Barcelona School of Building Construction-UPC, the Department of Architecture Technology-EPSEB-UPC, the School of Engineering MochisUAS, and finally the Civil Engineering School-UAM.

\section{References}

[1] C. Shi, Y. Wu, C. Riefler, and H. Wang, "Characteristics and pozzolanic reactivity of glass powders," Cement and Concrete Research, vol. 35, no. 5, pp. 987-993, 2005.

[2] A. Behrens, S. Giljum, J. Kovanda, and S. Niza, "The material basis of the global economy. Worldwide patterns of natural resource extraction and their implications for sustainable resource use policies," Ecological Economics, vol. 64, no. 2, pp. 444-453, 2007.

[3] C. B. Farinha, J. de Brito, R. Veiga, J. M. Fernández, J. R. Jiménez, and A. R. Esquinas, "Wastes as aggregates, binders or additions in mortars: Selecting their role based on characterization,” Materials, vol. 11, no. 3, p. 453, 2018.

[4] I. B. Topçu, A. R. Boğa, and T. Bilir, "Alkali-silica reactions of mortars produced by using waste glass as fine aggregate and admixtures such as fly ash and $\mathrm{Li}_{2} \mathrm{CO}_{3}$," Waste Management, vol. 28 , no. 5 , pp. $878-84,2008$.

[5] Y. Shao, T. Lefort, S. Moras, and D. Rodriguez, "Studies on concrete containing ground waste glass," Cement and Concrete Research, vol. 30, no. 1, pp. 91-100, 2000.

[6] S.-B. Park and B.-C. Lee, "Studies on expansion properties in mortar containing waste glass and fibers," Cement and Concrete Research, vol. 34, no. 7, pp. 1145-1152, 2004.

[7] T.-C. Ling, C.-S. Poon, and S.-C. Kou, "Feasibility of using recycled glass in architectural cement mortars," Cement and Concrete Research, vol. 33, no. 8, pp. 848-854, 2011.

[8] P. S. Bhandari and K. M. Tajne, "Use of waste glass in cement mortar," International Journal of Civil and Structural Engineering, vol. 3, no. 4, pp. 704-711, 2013.

[9] A. Khmiri, M. Chaabouni, and B. Samet, "Chemical behaviour of ground waste glass when used as partial cement replacement in mortars," Construction and Building Materials, vol. 44, pp. 74-80, 2013.

[10] N. Degirmenci, A. Yilmaz, and O. A. Cakir, "Utilization of waste glass as sand replacement in cement mortar," Indian Journal of Engineering and Materials Sciences, vol. 18, no. 4, pp. 303-308, 2011.

[11] R. Idir, M. Cyr, and A. Tagnit-Hamou, "Use of fine glass as ASR inhibitor in glass aggregate mortars," Construction and Building Materials, vol. 24, no. 7, pp. 1309-1312, 2010.

[12] C. S. Poon and T. C. B. Ling, "Use of Recycled Glass in Architectural Mortars," Journal of Wuhan University of Technology, vol. 32, no. 17, pp. 231-234, 2010.

[13] A. Karamberi and A. Moutsatsou, "Participation of coloured glass cullet in cementitious materials," Cement and Concrete Composites, vol. 27, no. 2, pp. 319-327, 2005.

[14] T.-C. Ling and C.-S. Poon, "Feasible use of large volumes of GGBS in $100 \%$ recycled glass architectural mortar," Cement and Concrete Composites, vol. 53, pp. 350-356, 2014.

[15] T.-C. Ling and C.-S. Poon, "Utilization of recycled glass derived from cathode ray tube glass as fine aggregate in cement mortar," Journal of Hazardous Materials, vol. 192, no. 2, pp. 451-456, 2011.

[16] K. H. Tan and H. Du, "Use of waste glass as sand in mortar: part I-fresh, mechanical and durability properties," Cement and Concrete Composites, vol. 35, no. 1, pp. 109-117, 2013. 
[17] V. Corinaldesi, G. Gnappi, G. Moriconi, and A. Montenero, "Reuse of ground waste glass as aggregate for mortars," Waste Management, vol. 25, no. 2, pp. 197-201, 2005.

[18] G. Lee, T.-C. Ling, Y.-L. Wong, and C.-S. Poon, "Effects of crushed glass cullet sizes, casting methods and pozzolanic materials on ASR of concrete blocks," Construction and Building Materials, vol. 25, no. 5, pp. 2611-2618, 2011.

[19] T.-C. Ling and C.-S. Poon, "Properties of architectural mortar prepared with recycled glass with different particle sizes," Materials \& Design, vol. 32, no. 5, pp. 2675-2684, 2011.

[20] T.-C. Ling and C.-S. Poon, "Effects of particle size of treated CRT funnel glass on properties of cement mortar," Materials and Structures, vol. 46, no. 1, pp. 25-34, 2012.

[21] T.-C. Ling and C.-S. Poon, "A comparative study on the feasible use of recycled beverage and CRT funnel glass as fine aggregate in cement mortar," Journal of Cleaner Production, vol. 29-30, pp. 46-52, 2012.

[22] A. M. Matos and J. Sousa-Coutinho, "Durability of mortar using waste glass powder as cement replacement," Construction and Building Materials, vol. 36, pp. 205-215, 2012.

[23] R. B. C. Sales, F. A. Sales, E. P. Figueiredo, W. J. Dos Santos, N. D. S. Mohallem, and M. T. P. Aguilar, "Durability of Mortar Made with Fine Glass Powdered Particles," Adv. Mater. Sci. Eng., vol. 2017, article 3143642, 9 pages, 2017.

[24] L. A. Pereira-de-Oliveira, J. P. Castro-Gomes, and P. M. S. Santos, "The potential pozzolanic activity of glass and red-clay ceramic waste as cement mortars components," Construction and Building Materials, vol. 31, pp. 197-203, 2012.

[25] Z. Hui and W. Sun, "Study of properties of mortar containing cathode ray tubes (CRT) glass as replacement for river sand fine aggregate," Construction and Building Materials, vol. 25, no. 10, pp. 4059-4064, 2011.

[26] V. Corinaldesi, A. Nardinocchi, and J. Donnini, "Reuse of recycled glass in mortar manufacturing," European Journal of Environmental and Civil Engineering, vol. 20, no. 1, pp. 140-151, 2016.

[27] Z. Hui, C. S. Poon, and T. C. Ling, "Properties of mortar prepared with recycled cathode ray tube funnel glass sand at different mineral admixture," Construction and Building Materials, vol. 40, pp. 951-960, 2013.

[28] H. Öznur Öz, H. Erhan Yücel, and M. Güneş, "Comparison of glass powder and fly ash effect on the fresh properties of selfcompacting mortars," IOP Conference Series: Materials Science and Engineering, vol. 245, article 032036, 2017.

[29] P. Penacho, J. de Brito, and M. R. Veiga, "Physico-mechanical and performance characterization of mortars incorporating fine glass waste aggregate," Cement and Concrete Composites, vol. 50, pp. 47-59, 2014.

[30] M. Bentchikou, S. Bouriah, N. Hamdane, F. Debieb, and O. Boukendakdji, "Comparative study of the properties of mortars with recycled glass aggregates incorporated by addition and substitution," Energy Procedia, vol. 139, pp. 499504, 2017.

[31] H. Du and K. H. Tan, "Concrete with recycled glass as fine aggregates," ACI Materials Journal, vol. 111, no. 1, pp. 47-58, 2014.

[32] A. R. G. de Azevedo, J. Alexandre, E. B. Zanelato, and M. T. Marvila, "Influence of incorporation of glass waste on the rheological properties of adhesive mortar," Construction and Building Materials, vol. 148, pp. 359-368, 2017.

[33] ASTM International, C144-99, Standard Specification for Aggregate for Masonry Mortar, ASTM International, West Conshohocken, PA, USA, 1999.
[34] F. G. Cabrera-Covarrubias, J. M. Gómez-Soberón, J. L. Almaral-Sánchez, R. Corral-Higuera, A. NavarroEzquerra, and M. Tous-Coll, "Characterization of three recycled materials for alternative use of mortars," International Journal of Sustainable Materials, Processes \& ECOEfficient, vol. 1, no. 3, pp. 13-17, 2014.

[35] ASTM International, C128-04a, Standard Test Method for Density, Relative Density (Specific Gravity), and Absorption, ASTM International, West Conshohocken, PA, USA, 2004.

[36] ASTM International, C136-06, Standard Test Method for Sieve Analysis of Fine and Coarse Aggregates, ASTM International, West Conshohocken, PA, USA, 2006.

[37] ASTM International, C117-95, Standard Test Method for Materials Finer than 75- $\mu m$ (No. 200) Sieve in Mineral, ASTM International, West Conshohocken, PA, USA, 1995.

[38] AENOR, UNE-EN 197-1, Cemento Parte 1: Composición, especificaciones $y$ criterios de conformidad de los cementos comunes, AENOR, Madrid, Spain, 2011.

[39] ASTM International, C305-06, Mechanical Mixing of Hydraulic Cement Pastes and Mortars of Plastic Consistency, ASTM International, West Conshohocken, PA, USA, 2006.

[40] ASTM International, C1437-99, Standard Test Method for Flow of Hydraulic Cement Mortar, ASTM International, West Conshohocken, PA, USA, 1999.

[41] ASTM International, C230/C230M-03, Standard Specification for Flow Table for Use in Tests of Hydraulic Cement, ASTM International, West Conshohocken, PA, USA, 2003.

[42] ASTM International, C109/C109M-05, Standard Test Method for Compressive Strength of Hydraulic Cement Mortars, ASTM International, West Conshohocken, PA, USA, 2005.

[43] ASTM International, C231-08b, Standard Test Method for Air Content of Freshly Mixed Concrete by the Pressure Method, ASTM International, West Conshohocken, PA, USA, 2008.

[44] ASTM International, C185-99, Standard Test Method for Air Content of Hidraulic Cement Mortar, ASTM International, West Conshohocken, PA, USA, 2001. 


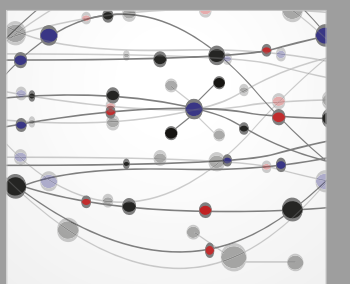

The Scientific World Journal
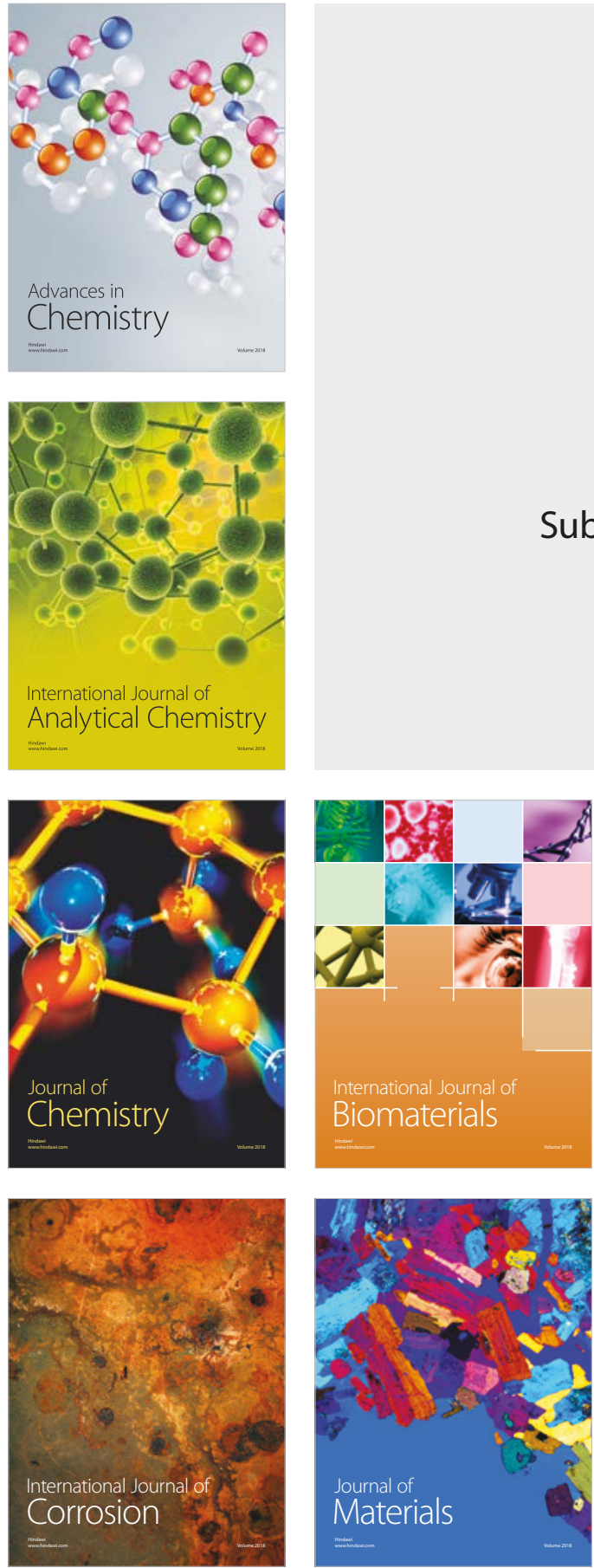

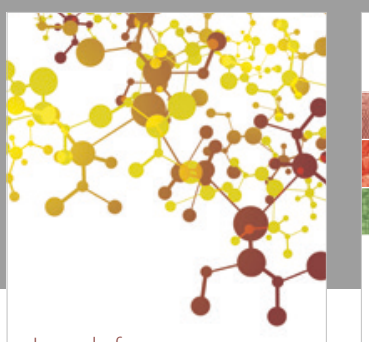

Journal of

Applied Chemistry
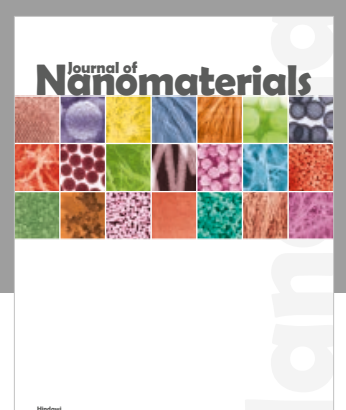

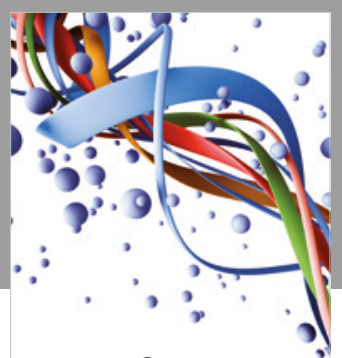

Scientifica

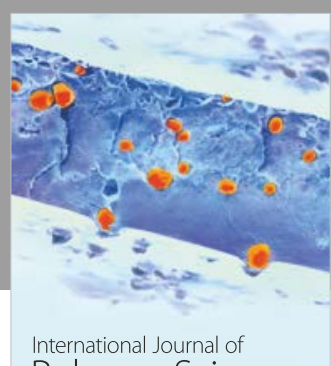

Polymer Science

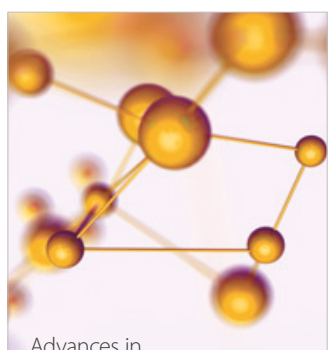

Physical Chemistry
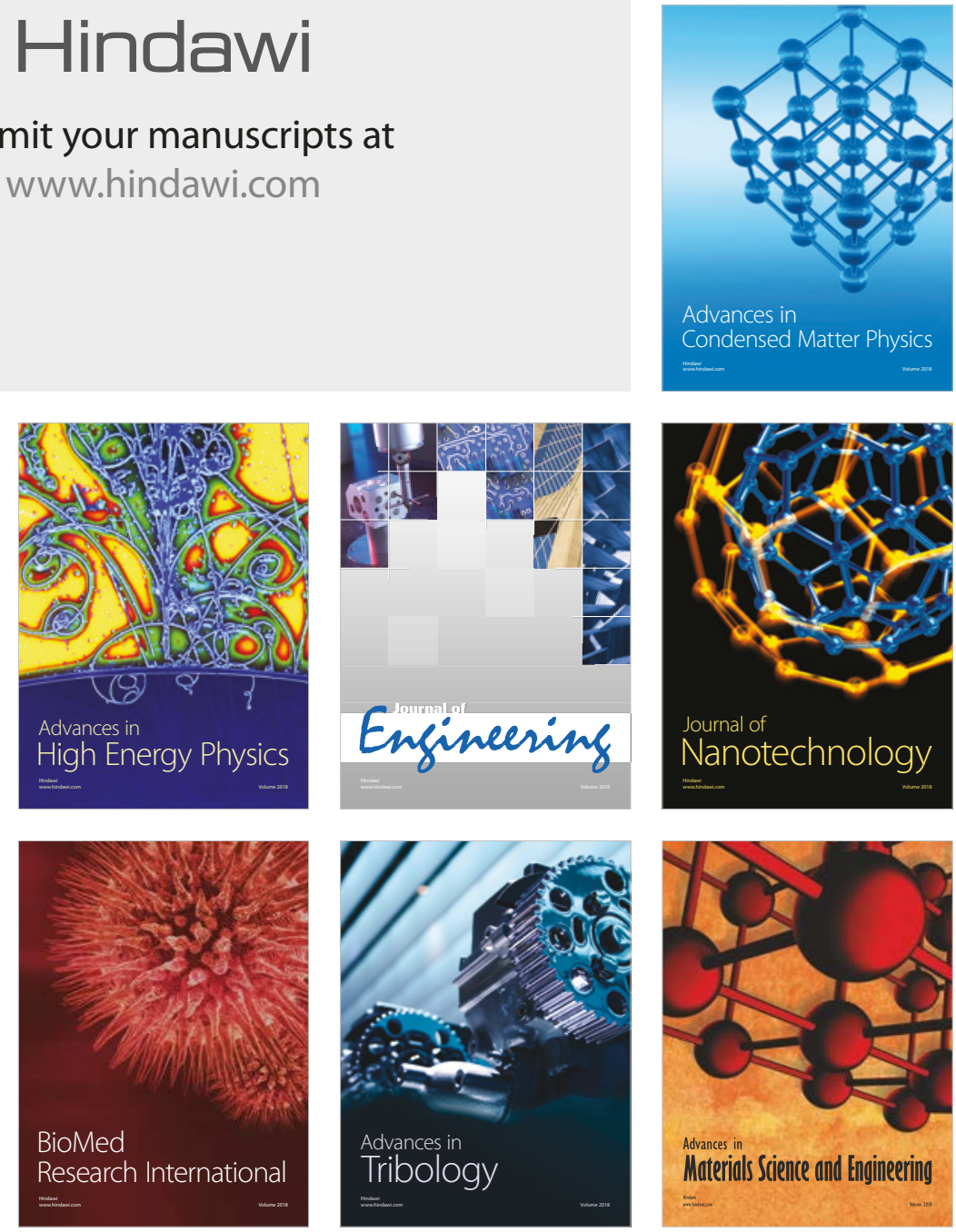